\title{
Phrasal Verb Combinations in Corpus-Based Studies: A Critical Review
}

\author{
Abdolvahed Zarifi (Corresponding author) \\ Department of Language and Humanities Education, Faculty of Educational Studies \\ Universiti Putra Malaysia, 43400 UPM SERDANG, Selangor, Malaysia \\ Tel: 60-136-698-284_ E-mail: vahed_zarifi@yahoo.com \\ Jayakaran Mukundan \\ Department of Language and Humanities Education, Faculty of Educational Studies \\ Universiti Putra Malaysia, 43400 UPM SERDANG, Selangor, Malaysia \\ E-mail: jaya@educ.upm.edu.my
}

Received: 24-04-2013

doi:10.7575/aiac.ijalel.v.2n.4p.212
Accepted: 28-05-2013

Published: 01-07-2013

URL: http://dx.doi.org/10.7575/aiac.ijalel.v.2n.4p.212

\begin{abstract}
This study presents a critique of some of the corpus-based studies on phrasal verbs carried out in different types of corpora. Not only is it an attempt to provide the reader with some of the revealing findings these works have to offer but it also tends to critically discuss some of the methodological issues associated with them. It starts off discussing the works done on phrasal verbs in general corpora, then goes on to review the studies dealt with the combinations in learner corpora and ends up with looking into the research focused on the presentation of the phrasal verbs in ELT materials. It is hoped that the methodological issues addressed in the study would be taken into account by the interested researchers in their future research attempts.
\end{abstract}

Keywords: Corpus Linguistics, Phrasal Verbs, Corpora, Critical Review

\section{Introduction}

With recent studies in SLA highlighting the significance of vocabulary and multiword expressions in language learning, the direction of a considerable body of linguistic research began to shift from syntax and phonology to the neglected areas of the lexicon and multi-word expressions. Laufer (1997, p. 147) emphasizes this paradigm shift by stating "After decades of neglect, lexicon is now recognized as central to language acquisition process, native or non-native". Phrasal verbs as an aspect of the lexicon are one of the most prolific, productive and elusive structures among the multi-word expressions. Researchers with the help of high-powered computers, robust software and large electronic corpora have recently succeeded in better characterizing, distinguishing and categorizing these otherwise fuzzy phenomena that are ubiquitous in English (Hunston, 2002; Read, 2004).

The phrasal verb has been variously defined as a verb followed by a morphologically invariable particle functioning as a single grammatical form with an idiomatic meaning (Quirk, Greenbaum, Leech, \& Svartvik, 1985), combination of a verb and a particle or a preposition forming a unit of meaning (Cowie \& Mackin, 2001), a two-word verb that functions as a single verb (Celce-Murcia and Larsen-Freeman, 1999), or a structure consisting of a verb proper and a morphologically invariable particle that functions as a single lexical and semantic unit (Darwin \& Gray, 1999). These structures are syntactically categorized as transitive/intransitive (e. g. He looked up the word/He sat down) and separable/inseparable combinations (e.g. He turned on the light $\backslash H e$ turned the light on/I came across some old letters $\backslash * \mathrm{I}$ came some old letters across). They are also semantically described as literal (sit down), idiomatic (give up), and aspectual (clean up) (Celce-Murcia \& Larsen-Freeman, 1999).

Literature has witnessed an extensive body of research on the underlying structure, grammar, meaning, and learning problems associated with the phrasal verbs (Bolinger, 1971; Celce-Murcia \& Larsen-Freeman, 1999; Dagut \& Laufer, 1985; Fraser, 1976; Hulstijn \& Marchena, 1989; Jackendoff, 2002; Laufer \& Eliasson, 1993; Liao \& Fukuya, 2004; Quirk, et al., 1985; Siyanova \& Schmitt, 2007; Sjoholm, 1995; Zoerner, 1996). The present critical review, nonetheless, homes in on a meta-analysis of the corpus-based studies dealing with these combinations in different general, learner and pedagogic corpora.

\section{Study of Phrasal Verbs in General or Reference Corpora}

Among the several recent attempts addressing the identification of English phrasal verbs based on corpus findings, one can refer to such well-known dictionaries as the Longman Dictionary of Phrasal Verbs, the Collins Cobuild Dictionary of Phrasal Verbs, NTC's Dictionary of Phrasal Verbs and Other Idiomatic Verbal Phrases, the Cambridge International Dictionary of Phrasal Verbs, and the Oxford Dictionary of Phrasal Verbs. Authors of these outstanding collections have 
identified a large number of English phrasal verbs and provided descriptions of the combinations along with contextualized examples of each unit. While use has been made of natural corpus in the definition and exemplification of the structures in these works, information regarding range and frequency data about these combinations is almost missing. Readers are not informed about which forms are more frequent than others. Similarly, it is not specified whether the presentation order of the different meanings of a given form is in keeping with their frequency of occurrence in actual practice. Such information could, of course, be of high interest and help to materials developers, curriculum designers and teachers who may wish to prioritize these structures based on their usefulness to the interested ESL/EFL learners. Furthermore, neither are all these combinations and the different meanings of a given form of equal importance in the language.

In addition to the dictionaries of phrasal verbs, there exists a wide range of studies dealing with these combinations as used in different types of corpora. The Longman Grammar (Biber, et al., 1999) is one of the most important works dealing with phrasal verbs with emphasis upon the principles set out by corpus linguistics. To them, phrasal verbs are multi-word units consisting of a verb followed by an adverbial particle with core spatial or locative meanings that tend to assume extended meanings in different contexts. Biber et al. make a distinction between phrasal verbs (Verb + Adverbial Particle, e.g. pick up), prepositional verbs (Verb + Preposition e.g. look at) and phrasal-prepositional verbs (Verb + Particle + Preposition e.g. get away with). They also enumerate a number of semantic and structural criteria such as adverb insertion, stress patterns, passive formation, relative clause formation, prepositional fronting, whquestion formation, and particle movement to distinguish the various types of these combinations.

The Longman Grammar includes all the phrasal verbs with a frequency count of over 40 times per million words in at least one register of the Longman Spoken and Written English Corpus (LSWE). This work sheds some new light on the frequency counts of the phrasal verbs and their constituents. For instance, it has developed a list of 31 most frequent phrasal verbs including, among others, combinations like COME ON, GET UP, SIT DOWN, GO OFF, PICK UP, PUT ON,FIND OUT, STAND UP, etc. Likewise, the most productive verbs in combining with adverbial particles to form phrasal verbs appear to be COME and PUT (each combining with 12 different particles), GET (combining with 11 different particles), GO (combining with 10 different particles) and TAKE (combining with 9 different particles). In a similar way, UP, OUT, ON, IN, OFF and DOWN are reported to be the 6 top frequent adverb particles. In addition, they have managed to classify the phrasal verbs in terms of their semantic domains such as activity (GET UP, PUT ON), mental (FIND OUT), communication (POINT OUT), occurrence (COME OFF), copular (TURN OUT) and aspectual (GO ON), with activity forms being the most common (75\%) especially in conversation and fiction types. Register-related frequency of the most prolific phrasal verbs is also addressed.

While Gardner and Davies (2007) claim that this work offers the best treatment of relative frequency of phrasal verbs, the development process of their most frequent list is in a way unconvincing. To put it into perspective, missing in the development of the list is the account of the range of these combinations. The authors have included items in the collection if only they have occurred over forty times in at least one register; however, following Nation and Waring (1997), an item is more useful if it has a low frequency of occurrence but a wider range of use. Furthermore, their definition of the phrasal verbs and inclusion of the combinations as phrasal verbs turn out to be inconsistent. To illustrate the point, the definition they have offered excludes as phrasal verbs a large number of combinations that are considered as literal phrasal verbs based the other definitions (Quirk et al. 1985; Celce-Murcia and Larsen-Freeman, 1999; Darwin \& Gray, 1999; Cowie and Mackin, 2001); yet, they have included a number of these literal forms in their list. While they consider some forms like 'COME BACK' as intermediate acting both as phrasal verbs and free forms based on the degree of their semantic idiomaticity, other literal forms like 'WALK IN' and 'MOVE OUT' were considered as phrasal verbs. Finally, the work remains silent on how different forms of a single combination like 'RUN UP' are distinguished from each other in the strings 'He RAN UP a huge bill' and 'He RAN UP to help the man'. While, 'UP' is a real particle in 'He RAN UP a huge bill' since it forms a whole unit with its preceding lexical verb, it is an adverb particle in 'He RAN UP to help the man' as it enjoys a separate grammatical and semantic status from its preceding verb.

Gardner and Davies (2007) conducted an exploratory corpus-based study of phrasal verbs in the mega corpus of the BNC. In order to do away with the disagreement about the phrasal verb combinations acknowledged by scholars, they decided upon a more objective definition of the phrasal verb that included any combination in the BNC of a lexical verb proper and an either contiguous or non-contiguous adverbial particle. Pedagogically speaking, this study was carried out, the researchers maintain, with a view to answering "the where-do-we-start question so often asked by English language learners, teachers, curriculum designers, and materials developers" (Gardner \& Davies, 2007, p. 353).

Having converted the grammatically tagged version of the BNC into a format that could be imported into Microsoft SQL Server, they ran software queries to seek out possible answers to the research questions. Findings indicated that combination of a small number of 20 lexical verbs with 8 adverbial particles (160 cases) accounted for more than one half of the 518,923 phrasal verb occurrences in the mega-corpus. Further analysis revealed that only 25 phrasal verbs accounted for nearly one third of all the phrasal-verb occurrences in the BNC, and 100 phrasal verbs accounted for more than one half of all such items. Subsequent semantic analyses of these 100 high-frequency phrasal verb forms, using WordNet (Miller, 2003), showed that they had potentially 559 variant meaning senses. Results also revealed that certain forms in particular, 'OUT, UP, DOWN, and BACK' tended to occur more as particles than as prepositions. In contrast, certain others like 'UNDER, BY, and ACROSS', rarely functioned as particles but most often did as 
prepositions. In view of the verbs, a few forms like 'PICK, POINT and CARRY' were more likely to occur in phrasal verb combinations than to act as single-word lexical items.

With regard to the findings of the study some remarks seem to be in order. While the study threw new light on the frequency counts of phrasal verbs and the lexical verbs and particles taking part in these combinations, it failed to deal with the issue of the range of these combinations across different genre types. Missing in the study is also the treatment of the different grammatical forms that these combinations are likely to assume. Investigation of the grammatical behavior of these combinations is an important issue as they may fall in a wide range of about fourteen different grammatical patterns (Zarifi, 2013). In addition, the researchers made use of the WordNet software for the semantic analysis of the data. However, while looking up synonyms in the software is less boring and less time-consuming than shuffling through dictionaries and looking up the long lists of different meanings of phrasal verbs, it does not provide a comprehensive range of all the possible meanings of each combination. Zarifi (2013) argues in favor of dictionaries like the Oxford Dictionary of Phrasal Verbs as the reference source for the semantic study of phrasal verbs. He illustrates that the WordNet offers no entry for some phrasal verbs like 'START OFF, INVITE ALONG, LOOK AHEAD' and many other forms. Likewise, while WordNet provides a total of eleven meanings for the combination 'GET OFF', the dictionary presents about twenty one different meanings for the same construction (Zarifi, 2013). Moreover, as the writers indicate, due to the relatively infrequent occurrences of phrasal verbs with longer separations, they limited their attention to those of the two- (TAKE ON), three- (TAKE it ON), and four-word (TOOK the nodules BACK) varieties and ignored longer separations in the BNC. However, it is interesting to point out that particles are likely to move farther than this length scenario from their associated lexical verbs.

In another important recent study on phrasal verbs, Trebits (2009) explored the use of these combinations in English language documents of the European Union (EU). In order to determine the frequency counts of the phrasal verbs and their particle elements and to examine the number of word-senses of each unit in the corpus, she built an EU English Corpus of approximately 200,000 running words from the texts representing the fields of activities of the EU. Then she provided a list of all adverbial particles using comprehensive grammar books. With the help of the Concordancing function of the WordSmith Version 2.0 (Scott, 1997), she identified all the verb + adverbial particle combinations in the corpus and determined the number of times a particle-type functioned as an adverbial particle as opposed to a preposition or other grammatical devices. Knowing that some phrasal verbs may have multiple meanings depending on the context, she then went on to semantically analyze the most frequent phrasal verbs in the corpus.

Data analysis enabled the researcher to provide a list of the most productive lexical verbs and adverbial particles (APs) forming verb + particle constructions in the Corpus of CEUE. A total of 130 lexical verb-types and 14 particles were identified in a total of 1031 phrasal verb constructions. Considering the overall size of the corpus (about 200,000 tokens), this means one phrasal verb construction appeared in approximately every 200 words of text.

From the top 50 lexical verbs in the CEUE, eleven items, namely 'BASE, BRING, CALL, GO, MAKE, OPEN, PUT, REPORT, SET, TAKE and WORK' frequently appeared in phrasal verb constructions; moreover, some of them combined with the largest number of adverbial particles. For example, the verb 'TAKE' combined with 8 different particles in the CEUE to form phrasal verbs such as 'TAKE AWAY, TAKE BACK, TAKE FORWARD, TAKE OFF, TAKE ON, TAKE OUT, TAKE OVER and TAKE UP'. Interestingly, about half of the 25 most frequent phrasal verbs in the CEUE (e.g., SET, PUT, MAKE, FIND, TAKE, etc.) were among the 20 most frequent lexical verbs forming phrasal verb combinations in the BNC Written.

Semantic analysis of the data revealed that about one third of the most frequent phrasal verbs appeared to express more than one meaning in the CEUE. However, since the EU is in written form, the multiple-meaning phrasal verbs in the corpus used considerably fewer meanings than general English. For example, while the phrasal verb 'SET UP' had two different meanings in the CEUE, namely 'to start a business or organization' and 'to make the arrangements for something to happen', it conveys more than ten different senses in general English.

Although some of the findings of the study receive enough support from the literature, care should be exercised in interpreting the results. As the writer has remarked, an obvious limitation of the study was the size of the corpus. A larger sized corpus in both written and spoken forms could be a better representative of the EU English language. Moreover, the study failed to make any difference between different categories of phrasal verbs in terms of compositionality. As the EU is in formal written form, this is an important distinction to make in light of the research findings that highly idiomatic phrasal verbs feature more formal and written language than the spoken form.

\section{Study of Phrasal Verbs in Learner Corpora}

In addition to the studies on phrasal verbs in general corpora, there also exist a few studies dealing with them in learner corpora. In a cross-lingual study, Schneider (2004) investigated the use of the phrasal verbs in four recent sub-corpora of International Corpus of English from India, Singapore, the Philippines, and East Africa and compared these corpora with the British English ICE corpus to explore how the occurrence, frequency of occurrence, structural behavior, and productive use of these combinations vary among the different language contexts.

Data analysis showed that learners from Singapore tended to use phrasal verbs (68 cases per one million tokens) not only more than the ESL learners from other language contexts (29 in Tanzania, 26 in India and 35 in the Philippines) but also more than the native speakers (55). In addition, the non-Singaporean ESL learners' tendency towards using phrasal verbs turned out to be in inverse relationship with the degree of stylistic formality. While the Singaporean learners like the native speakers showed a heavy preference for the use of these combinations in spoken English, other 
ESL learners' use of the phrasal verbs was stylistically associated with more formal contexts. Moreover, he found that the ESL varieties were structurally distinct from $\mathrm{BrE}$ in that they showed preference for the use of particle element just adjacent to its lexical verb, tending to maintain the integrity of the phrasal verb combinations.

As to the productivity of phrasal verbs, Singaporean English employed remarkably a wider range of the potential word meanings associated with phrasal verbs than any other variety including BrE. Indian English roughly compared with $\mathrm{BrE}$ in terms of the number of meanings documented; however, the Philippines and East Africa proved to show a heavier reservation and reluctance towards using phrasal verbs.

Despite the insightful findings of the study, some methodological issues need to be taken into account. To begin with, with the prolific and ubiquitous nature of the phrasal verb combinations in mind, the number of items selected for investigation was really negligible. As the researcher has reported, 9 of the 20 combinations in one of the tests and 6 out of 20 forms in the other test did not yield any data at all, implying the inadequacy of sample representativeness or inappropriate selection of the combinations. Secondly, the researcher, just for practicality considerations, studied a limited number of grammatical patterns associated with the phrasal verb combinations. To put it into perspective, in order to study the grammatical variability across the varieties, he only opted for the structures featuring V+ Particle+ Noun and $\mathrm{V}+$ Noun + Particle configurations and excluded a large number of other plausible patterns such as intransitive combinations, passive structures, particle pronominal object forms and even transitive phrasal prepositional verb combinations. As a result, findings, let alone the issue of sampling representativeness, cannot be generalized to grammatical patterns beyond the very two patterns explored.

One of the studies extensively dealing with the use of phrasal verbs in learner corpora is Von's (2007) Ph D research project. In this large scale study, Von investigated the use of phrasal verbs in two sub-corpora of the International Corpus of Learner English (ICLE), namely the German (G-ICLE) and Italian (I-ICLE) components. He also compared the findings with the native speaker writings in the Louvain Corpus of Native English Essays (LOCNESS). Findings showed that German learners tended to use more phrasal verb constructions than not only the Italian subjects but also the native speakers. The German learners' high preference for the use of phrasal verbs was attributed to the fact that they tended to make use of the lexical verbs of Germanic origin. On the other hand, the Italian learners tended to avoid phrasal verbs simply because they preferred to use the verb forms of Latin provenance. The line of argument turns out to be justifiable due to the fact that phrasal verbs mostly form with lexical verbs of Germanic base and that Italian, unlike German, does not form phrasal verb structures.

Finally, in a recent corpus-based study, Akbari (2009) investigated the Malaysian ESL learners' use of phrasal verb combinations. The corpus of the study comprised a number of the secondary level students' narrative compositions sampled from the EMAS corpus. Data analysis enabled the researcher to conclude that the learners' use of phrasal verbs was inaccurate both in syntactic and semantic terms. He added that the learners used some phrasal verbs not specified in the prescribed curriculum. In a similar way, the learners tended to avoid using combinations of idiomatic type. Although the study dealt with a wide range of difficulties that the Malaysian learners experience in using the phrasal verb structures, it suffers from a number of methodological shortcomings.

First, the claimed low use of phrasal verbs by the learners can be somehow attributed to the representativeness of the corpus of the study. According to Biber (1993), a corpus should be large enough in size to represent the full range of text variability in the target population. This study, however, seems not to conform well to this very basic criteria since it has been carried out on a small-scale sample of the main corpus, namely, the narrative compositions. Use of these forms in the spoken sub-corpus of the EMAS has not been dealt with at all. This will bring the representativeness of the corpus under question. One more corpus related issue with the study has to do with its genre type. It dealt with only the narrative productions of the learners as the corpus contains only this very genre. It would be more revealing of the ESL learner treatment of phrasal verbs if other genres like description, definition, process, and other prose types were included. Third, most of the issues reported turned out not to be purely motivated by the challenging features of these notoriously mysterious structures. For instance, ESL learners have also been reported to experience difficulties with such issues as subject-verb agreement, tense aspect, verb form, etc. of single-word verbs. The results would have been more interesting if the study had mainly focused on more phrasal verb-related issues like choosing the wrong verb, choosing the wrong particle, the overuse of less frequent forms, incorrect collocating grammar, and restricted use that were established by Pye (1996). Fourth, the learners' limited mastery of the structures and their inappropriate application of the combinations in writing might have mirrored the inter-language systems they were developing in the process of learning (Liu, 2003). According to Selinker (1972), inter-language is a dynamic system which is subject to change and learner knowledge of language rules and features including phrasal verbs is open to amendments (Yang, 1999). Fifth, although the researcher managed to differentiate between the combinations in terms of their level of compositionality, the criteria underlying the classification of the different types of phrasal verbs are unclear. For example, identification of the combination 'BREAK OUT' as an aspectual form and that of the combination 'BREAK OFF' as an idiomatic unit throws the process of the semantic classification of the combinations into question. Finally, while Akbari (2009), following Celce-Murcia and Larsen-Freemam (1999), has attributed the learners' problem with these mysterious structures to the syntactic difference between the learners' native language and the English language and the challenging behavior of the combinations, one should not lose sight of the "how" of the selection and presentation of these structures in the instructional materials. That the students successfully produced combinations not introduced to them in their materials and vice versa might suggest that the presentation of these forms in the textbook materials was far from effective. 


\section{Study of Phrasal Verbs in Pedagogic Corpora}

With the phrasal verbs overwhelmingly present in the language and different collections available to choose from, curriculum designers and materials developers alike often feel frustrated with which phrasal verbs and how many of them to include. This sense of frustration is complicated by the limited volume of course books and the fact that not all of these phrases are of equal use to EFL/ESL learners. However, as these elements are crucial to successful language learning, any development of instructional materials includes a number of them. That being said, at issue is whether developers are really taking into account the corpus-based research findings in selecting and presenting these structures since it is often argued that corpus-based research allows for the principled decisions to be made about the evaluation and prioritization of the linguistic features in textbook materials (Barbieri \& Eckhardt, 2007).

In keeping up with the above argument, the selection and presentation of the phrasal verb combinations in the ELT corpora has also been investigated in different contexts. Examining a few ELT course books and reference materials dealing with phrasal verbs, Side (1990) argues that the difficulties associated with these combinations are sometimes increased by the way in which they are presented. According to Side, description of phrasal verbs in instructional materials often fail "to create learnable patterns" and they sometimes create "patterns of the wrong kind" (P. 150) as if there are no regularities with these combinations. Some course books provide lists of phrasal verbs formed around a specific lexical verb. Side even goes on to criticize dictionaries in dealing with these structures arguing that they go wrong in defining phrasal verbs at times. For instance, Collins Cobuild Dictionary gives one definition of 'OFF' as 'to indicate that something which has moved towards a surface and touched it moves away from it again' illustrated by items such as 'BOUNCED OFF' and 'REFLECTED OFF'. However, much, if not all, of this definition is carried by the verb rather than the particle. Likewise, 'UP' has been defined in Longman English Grammar as "confining/fastening/mending etc." exemplified by 'LOCK STH UP, STICK STH UP, PACK STH UP, etc'. Here again, the meaning is more conveyed by the verb than by the particle.

According to Side (1990), if the particle element is closely looked at, patterns start to emerge, rejecting the randomness assigned to phrasal verb constructions. She adds that it is sometimes necessary to think laterally, metaphorically, or even pictorially in searching for the related patterns. For instance, a meticulous look at the particle 'OFF' shows that it indicates 'distance in time or space, departure, removal, disconnection, and separation' as in: 'STRAIN OFF' the liquid (removal); The plane 'TOOK OFF' (departure); The meeting was 'PUT OFF' (distance in time) (Side, 1990, p. 147), and so on. Side admits that some of her discussion is rather speculated and hence linguistically suspect; yet, she argues that such speculation is pedagogically justifiable as learners, at times, make attempts to work out patterns that speed up learning and strengthen memory.

In addition, Darwin and Gray (1999) developed a list of the 20 most frequently occurring phrasal verbs in the BNC. Comparing the list with the phrasal verbs in a typical ESL grammar book, they found that only 3 of all the phrases in the textbooks matched the 20 phrasal verbs on the list. Likewise, Koprowski (2005) studied the use of phrasal verbs and other multiword expressions in three contemporary ELT course books. Although they were all developed as British general English materials for learners at the intermediate level, not even a single phrasal verb was found to be shared by the three books. Lamenting the lack of consistency among the textbooks, she observed that ELT materials developers do not follow any principled criteria in the process of vocabulary selection. In another recent study on the Malaysian ESL textbooks, Zarifi and Mukundan (2012) investigated the use of phrasal verb combinations in the spoken sections of the materials. Findings of the study revealed that both the selection and presentation of these combinations were inconsistent with their actual use in the BNC. They reported that textbooks contained combinations of extremely low frequency counts in general English and vice versa.

\section{Conclusion}

This review study has critiqued some of the studies dealing with the use of phrasal verbs in different corpus studies. Despite the merit of these studies and the insight they provide into a number of the features of phrasal verbs as a challenging aspect of the language, they were shown to be suffering from some methodological problems. First, some of these studies seem not to work consistently in their attempt to define and classify phrasal verbs. A large number of the structures that are included as phrasal verbs in one study are excluded from others simply because of their level of compositionality. It even happens that the same work fails to be consistent in its approach towards the classification of these combinations in terms of which forms constitute a phrasal verb (Biber et al., 1999) and how they are assigned semantic labels (Akbari, 2009). Second, those dealing with the semantic aspects of the combinations (Trebits, 2009; Darwin \& Gray, 1999) have made use of the WordNet software which turns out to be lacking both in terms of the number of phrasal verbs it represents and the number of definitions it offers for each combination (Zarifi, 2013). Third, some of the studies are questionable with regard to the size of the corpus they investigated (Akbari, 2009; Schneider, 2004; Trebits, 2009) and some others are suffering in terms of the scope of the forms they studied. For instance, Darwin and Gray (1999) limited their study to forms in which the particle element falls not farther than three words from its lexical verb and ignored other distance scenarios. Schneider (2004), in a similar way, just for manageability, focused upon the combinations featuring $\mathrm{V}+$ Particle + Noun and $\mathrm{V}+$ Noun + Particle configurations and ignored other plausible configurations like intransitive forms, passive structures, particle pronominal object forms, etc. Fourth, while frequency appeared to be of main focus in all of these studies, most of them (e.g. Darvin \& Gray, 1999; Trebits, 2009) ignored the issue of range in their treatment of the combinations. Finally, some of the studies on learner corpora (e.g. Akbari, 2009) dealt with the issues that are related to the use of verbal element in general rather than those purely motivated by the challenging features of these notoriously mysterious structures. 


\section{References}

Akbari, O. (2009). A corpus-based study on Malaysian ESL learners' use of phrasal verbs in narrative compositions. Universiti Putra Malaysia, Serdang.

Barbieri, F., \& Eckhardt, S. E. B. (2007). Applying corpus-based findings to form-focused instruction: The case of reported speech. Language Teaching Research, 11(3), 319-346.

Biber, D. (1993). Representativeness in corpus design. Literary and linguistic computing, 8(4), 243.

Biber, D., Johansson, S., Leech, G., Conrad, S., Finegan, E., \& Quirk, R. (1999). Longman grammar of spoken and written English: MIT Press.

Bolinger, D. (1971). The phrasal verb in English. Cambridge, MA: Harvard University Press.

Celce-Murcia, M., \& Larsen-Freeman, D. (1999). The grammar book: An ESL/EFL teacher's course. Boston: H \& H Publishers.

Cowie, A., \& Mackin, R. (2001). Oxford dictionary of phrasal verbs. Oxford: Oxford University Press.

Dagut, M., \& Laufer, B. (1985). Avoidance of phrasal verbs-A case for contrastive analysis. Studies in second language acquisition, 7(1), 73-79.

Darwin, C., M., \& Gray, L. S. (1999). Going after the Phrasal Verb: An Alternative Approach to Classification. TESOL Quarterly, 33(1), 65-83.

Fraser, B. (1976). The verb-particle combination in English: Academic Press.

Gardner, D., \& Davies, M. (2007). Pointing Out Frequent Phrasal Verbs: A Corpus-Based Analysis. TESOL Quarterly, 41, 339-359.

Hulstijn, J., \& Marchena, E. (1989). Avoidance: Grammatical or Semantic Causes. Studies in second language acquisition, 11(3), 241-255.

Hunston, S. (2002). Corpora in applied linguistics. Cambridge: Cambridge University Press.

Jackendoff, R. (2002). English particle constructions, the lexicon,and the autonomy of syntax. In N. Dehe, R. Jackendoff, A. McIntyre \& S. Urban (Eds.), Verb-particle explorations. New York: Mouton de Gruyter.

Laufer, B. (1997). The lexical plight in second language reading: words you don't know, words you think you know and words you can't guess Second language vocabulary acquisition: A rational for pedagogy (pp. 20-52).

Laufer, B., \& Eliasson, S. (1993). What causes avoidance in L2 learning: L1-L2 difference, L1-L2 similarity, or L2 complexity Studies in Second Language Acquisition, 15, 35-48.

Liao, Y., \& Fukuya, Y. (2004). Avoidance of phrasal verbs: The case of Chinese learners of English. Language learning, 54(2), 193-226.

Liu, D. (2003). The Most Frequently Used Spoken American English Idioms: A Corpus Analysis and Its Implications. TESOL Quarterly, 37(4), 671-700.

Nation, P., \& Waring, R. (1997). Vocabulary size, text coverage and word lists Vocabulary: Description, acquisition and pedagogy (pp. 6-19).

Pye, G. (1996). Don't give up, look it up!Defining phrasal verbs for the learner of English. Paper presented at the EURALEX 96, Goteborg.

Quirk, R., Greenbaum, S., Leech, G., \& Svartvik, J. (1985). A comprehensive grammar ofthe English language London: Longman.

Read, J. (2004). Research in teaching vocabulary. Annual Review of Applied Linguistics, 24, 146-161.

Schneider, E. W. (2004). How to trace structural nativization: particle verbs in world Englishes. World Englishes, 23(2), 227-249.

Selinker, L. (1972). Interlanguage. IRAL-International Review of Applied Linguistics in Language Teaching, 10(1-4), 209-232.

Side, R. (1990). Phrasal verbs: sorting them out. ELT Journal, 44(2), 144-152.

Siyanova, A., \& Schmitt, N. (2007). Native and nonnative use of multi-word vs. one-word verbs. IRAL-International Review of Applied Linguistics in Language Teaching, 45, 119-139.

Sjoholm, K. (1995). The influence of crosslinguistic, semantic, and input factors on the acquisition of English phrasal verbs: A comparison between Finnish and Swedish learners at an intermediate and advanced level. Abo: Abo Akademi University Press.

Trebits, A. (2009). The most frequent phrasal verbs in English language EU documents - A corpus-based analysis and its implications. System, 37(3), 470-481.

Von, V. (2007). Phrasal verbs in learner English: A corpus-based study of German and Italian students. AlbertLudwigs-Universitat, Freiburg.

Yang, D. (1999). Interlanguage Errors and Cross-linguistic Influence--A Corpus-based Approach to the Chinese EFL Learners' Written Production. Guangdong University of Foreign Studies

Zarifi, A. (2013). A corpus-based study of phrasal verbs in Malaysian ESL textbooks. UPM, Selangor.

Zarifi, A., \& Mukundan, J. (2012). Phrasal verbs in Malaysian ESL textbooks. English Language Teaching, 5(5), 9-18. Zoerner, E. (1996). English verb-particle constructions: Two types, two structures. Kansas Working Papers in Linguistics, 21, 123-141. 